CLINICAL STUDY

\title{
Early treatment with GH alone in Turner syndrome: prepubertal catch-up growth and waning effect
}

\author{
Malgorzata Wasniewska, Filippo De Luca, Rosalba Bergamaschi ${ }^{1}$, Maria Pia Guarneri ${ }^{2}$, Laura Mazzanti ${ }^{1}$, \\ Patrizia Matarazzo ${ }^{3}$, Antonella Petri ${ }^{4}$, Giuseppe Crisafulli, Giuseppina Salzano and Fortunato Lombardo \\ Department of Pediatrics, University of Messina, Messina, Italy, ${ }^{1}$ Department of Pediatrics, University of Bologna, Bologna, Italy, ${ }^{2}$ Department of \\ Pediatrics, University of Milan, Milan, Italy, ${ }^{3}$ Regina Margherita Hospital of Turin, Turin, Italy and ${ }^{4}$ Department of Pediatrics, University of Novara, \\ Novara, Italy on behalf of the Italian Study Group for Turner syndrome
}

(Correspondence should be addressed to F De Luca, Dipartimento di Scienze Pediatriche, Mediche e Chirurgiche, Policlinico Universitario di Messina, via Consolare Valeria, 98123 Messina-Gazzi, Italy; Email: wasniewska@yahoo.it)

\begin{abstract}
Objective: In order to ascertain the advantages of early GH treatment in Turner syndrome (TS), we started a prospective study aimed at evaluating prepubertal height gain in a cohort of 29 girls who were treated with the same pro-kilo GH dose (1.0 IU/kg per week) since they were less than 6 years old and for at least 5 years before entering puberty.

Patients and design: Following a minimum of 6 months of baseline observations, 29 girls with TS were enrolled for this prospective study provided that they (a) were less than 6 years old, (b) were below -1.0 standard deviation score (SDS) for height, (c) had a projected adult height (PAH) lower than the respective target height (TH) and (d) had a height velocity (HV) lower than - 1.0 SDS. All the selected girls underwent a 5-year treatment with biosynthetic GH at a stable dose of $1.0 \mathrm{IU} / \mathrm{kg}$ per week and were periodically measured during the treatment period in order to evaluate height, HV and $\mathrm{PAH}$.

Results: After a dramatic acceleration during the 1st year, HV was attenuated during the subsequent years, reaching its nadir at the 5 th year. Height deficiency under therapy progressively decreased from entry onwards, shifting from $-2.4 \pm 0.7$ to $-1.0 \pm 1.2$ SDS. In the same period, mean PAH progressively increased, although after 5 years it remained lower than the average $\mathrm{TH}$.

Conclusions: (a) An effective growth-promoting strategy in TS should be based on early GH treatment, as suggested by our results. (b) This strategy could result in a prepubertal normalization of height, thus allowing the appropriate timing for the induction of puberty. (c) An initial GH dose of $1.0 \mathrm{IU} / \mathrm{kg}$ per week may be suitable during the first years of therapy, as shown by our data documenting an important waning effect of GH therapy only after the 4th year of treatment. (d) No acceleration of bone maturation was observed under this treatment regimen.
\end{abstract}

European Journal of Endocrinology 151 567-572

\section{Introduction}

Turner syndrome (TS) is the most common sex chromosome abnormality in females, affecting an estimated 3\% of all females conceived and approximately one out of every 1500-2500 live-born females (1). One of the most prevalent and salient features of TS is extremely short stature. The average height of untreated women with TS is $143 \mathrm{~cm}$, approximately $20 \mathrm{~cm}$ below that of adult women in the general population and $20 \mathrm{~cm}$ below genetic target height (TH).

Although girls with TS are not growth hormone (GH) deficient, GH administration is known to accelerate growth in a dose-dependent way (2). In most girls with TS, puberty has to be induced by estrogen therapy. The optimal age to start estrogen treatment is still a point of discussion. Postponing the onset of this therapy, in order to prolong the growth phase as well as to achieve a longer period of total GH exposure, has been suggested (3). However, an excessive delay in pubertal development may have serious psychosocial consequences in these patients already stigmatized by short stature and dysmorphic features (4).

An alternative means to prolong the estrogen-free $\mathrm{GH}$ treatment interval may be the early onset of $\mathrm{GH}$ therapy (5).

In order to ascertain the advantages of early GH treatment in TS, we started a prospective study aimed at evaluating the prepubertal height gain in a cohort of 29 girls who were treated with the same pro-kilo GH dose $(1.0 \mathrm{IU} / \mathrm{kg}$ per week) since they were less than 6 years of age and for at least 5 years before entering puberty. 
The aim of this study was to verify whether early GH therapy allows full catch-up growth before starting the induction of puberty or its spontaneous onset.

\section{Patients and methods}

\section{Study population}

Following a minimum of 6 months of baseline auxological observations, 29 girls with karyotypes consistent with TS were enrolled for this prospective study by five Italian Centers of Pediatric Endocrinology during the period 1995 to 1998. Subjects were eligible to enter the study provided that at entry they (a) were younger than 6 years, (b) were below - 1.0 standard deviation score (SDS) for height, (c) had a projected adult height $(\mathrm{PAH})$ lower than the respective $\mathrm{TH}$ and (d) had a height velocity (HV) lower than - 1.0 SDS.

Exclusion criteria were (a) Y-chromosome material on the karyotype, (b) they had been treated with previous growth-promoting therapies and (c) they had had associated endocrine or metabolic disorders or other systemic illnesses.

The patients' karyotypes and their individual and average data concerning chronological age (CA) and auxological parameters at entry are reported in Table 1. Twenty-one patients $(72.4 \%)$ had a 45,XO karyotype whereas the remaining eight girls displayed variants of X-chromosome abnormalities (partial deletions or mosaics) (Table 1). Average baseline CA was $4.3 \pm 1.0$ years (range 1.4-5.9) (Table 1). Bone age (BA) at entry was on average slightly retarded, with a mean BA:CA ratio of $0.9 \pm 0.5$ years. Twenty-two patients $(75.9 \%)$ were at least 2 SDS below the mean for CA of normal girls and six of them (20.6\%) were at least 3 SDS below the mean. The remaining seven girls $(24.1 \%)$ were between -1.2 and -1.9 SDS (Table 1$)$. Only two of 28 subjects $(7.1 \%)$ showed a $\mathrm{PAH}$ higher than $150 \mathrm{~cm}$ (Table 1).

\section{Study design}

All the selected patients underwent a 5-year hormonal treatment with biosynthetic human GH (Genotropin; Pharmacia and Upjohn, Stockholm, Sweden) which was given subcutaneously once daily at bedtime, using a pen injection system, at a stable dose of $1.0 \mathrm{IU} / \mathrm{kg}$ per week $(0.33 \mathrm{mg} / \mathrm{kg}$ per week). Every 3 months the total $\mathrm{GH}$ dose was adjusted according to weight variations. No other hormonal therapy was given during this 5-year period.

All the girls were clinically monitored at their participating center every 3 months during the whole study period. Procedures performed at clinic visits

Table 1 Karyotype, CA, height (references were healthy girls), $\mathrm{PAH}$ and $\mathrm{TH}$ at the onset of therapy.

\begin{tabular}{|c|c|c|c|c|}
\hline Karyotype & CA (years) & Height (SDS) & PAH (cm) & TH $(\mathrm{cm})$ \\
\hline $45, \mathrm{X0}$ & 1.4 & -2.0 & - & 156.2 \\
\hline $45, \times 0$ & 2.6 & -2.4 & 145 & 149.5 \\
\hline $45, \times 0$ & 2.6 & -2.0 & 147 & 158.1 \\
\hline $45, \times 0$ & 2.9 & -1.2 & 152 & 157.2 \\
\hline $45, \times 0$ & 3.1 & -2.4 & 145 & 157.2 \\
\hline $45, \times 0$ & 3.6 & -2.5 & 145 & 163.4 \\
\hline $45, \times 0$ & 3.7 & -4.0 & 138 & 157.2 \\
\hline $45, X 0,46, X X$ & 3.8 & -1.9 & 145 & 155.5 \\
\hline $45, X 0,46, X \operatorname{del}(X) p 22.1$ & 4.2 & -2.8 & 143 & 150.0 \\
\hline $45, \times 0$ & 4.2 & -2.0 & 144 & 161.5 \\
\hline $45, \times 0$ & 4.2 & -3.7 & 138 & 160.7 \\
\hline $45, \times 0$ & 4.2 & -1.9 & 145 & 155.0 \\
\hline $45, \times 0$ & 4.3 & -1.9 & 145 & 167.0 \\
\hline $45, X 0,46, X i(X q)$ & 4.3 & -2.5 & 143 & 154.6 \\
\hline $45, \times 0$ & 4.5 & -4.0 & 138 & 157.2 \\
\hline $46, X X+\operatorname{del}(X), t(X: p e G)$ p22 sol, 45,X0 & 4.5 & -2.3 & 144 & 159.0 \\
\hline $45, \mathrm{X0}, 46, \mathrm{Xi}(\mathrm{Xq})$ & 4.7 & -3.2 & 139 & 157.5 \\
\hline $45, \times 0$ & 4.7 & -3.0 & 143 & 155.5 \\
\hline $45, \times 0$ & 4.8 & -1.4 & 152 & 168.3 \\
\hline $45, X 0,46, X X$ & 4.8 & -2.1 & 145 & 156.0 \\
\hline $45, \times 0$ & 4.9 & -2.5 & 143 & 162.5 \\
\hline $45, \times 0$ & 5.0 & -2.4 & 143 & 160.9 \\
\hline $45, \times 0$ & 5.0 & -3.0 & 143 & 156.9 \\
\hline $45, \times 0$ & 5.3 & -2.1 & 143 & 164.3 \\
\hline $45, \times 0$ & 5.3 & -1.8 & 145 & 162.6 \\
\hline $45, \times 0$ & 5.5 & -1.6 & 145 & 154.7 \\
\hline $46, X t(13: X)$ & 5.7 & -2.3 & 143 & 156.8 \\
\hline $45, \times 0$ & 5.8 & -2.9 & 139 & 154.7 \\
\hline $45, X 0,46, X X$ & 5.9 & -2.6 & 139 & 163.1 \\
\hline Mean & 4.3 & -2.4 & 143.5 & 158.4 \\
\hline S.D. & 1.0 & 0.7 & 3.5 & 4.9 \\
\hline
\end{tabular}


included a complete physical examination, assessment of pubertal stage and auxological measurements. BA was systematically evaluated in all girls only at entry and at the end of the study period. Patients' CA at the end of our observation period ranged from 6.4 to 10.9 years (mean 9.3 \pm 1.0 ).

This study protocol was reviewed and approved by the institutional review boards at each center, and a written form was used to document the informed consent of the patients' parents.

\section{Methods}

Height measurements of the patients and their parents were performed by either supine or standing stadiometers (Harpenden and Holtain Ltd, Crymych Arms, Dyfed, UK). Height and HV SDS were calculated according to the standards of Sempè et al. (6). TH was calculated by (father's height + mother's height \pm 13$) / 2(7)$ and assessed as SDS by French standards (6). The target range was defined as $\mathrm{TH} \pm 8.5 \mathrm{~cm}$ (7). Height gained as a consequence of therapy was determined by subtracting the pretreatment height SDS from the height SDS recorded at each evaluation during treatment. PAH was evaluated according to the method assessed by Lyon et al. (8), based on growth curves of untreated patients with TS. In one patient (no. 1 of Table 1), PAH could not be calculated at entry, because of the age being less than 2 years. The BA of all the girls was assessed by the same investigator using X-ray of the left hand, according to the method of Greulich \& Pyle (9).

\section{Statistical analysis}

The data are expressed as means \pm s.D. Comparisons between groups were made by both unpaired and paired Student's t-test. Correlations were performed by Pearson's test. Differences in the proportions of patients were made by the $\chi^{2}$ test. In all the tests, $P$ values $<0.05$ were considered to reflect statistical significance.

The study design and methods were approved by our University Hospitals' Ethic Committees.

\section{Results}

During the overall GH treatment period no patients exhibited clinical signs compatible with the onset of puberty.

\section{Height and bone maturation velocity}

With respect to the baseline growth rate, HV underwent a dramatic acceleration during the 1st year of $\mathrm{GH}$ therapy (Fig. 1). If compared with the HV peak recorded during the 1st year of treatment, HV was attenuated during the 2 nd $(P<0.05)$ and the 3rd

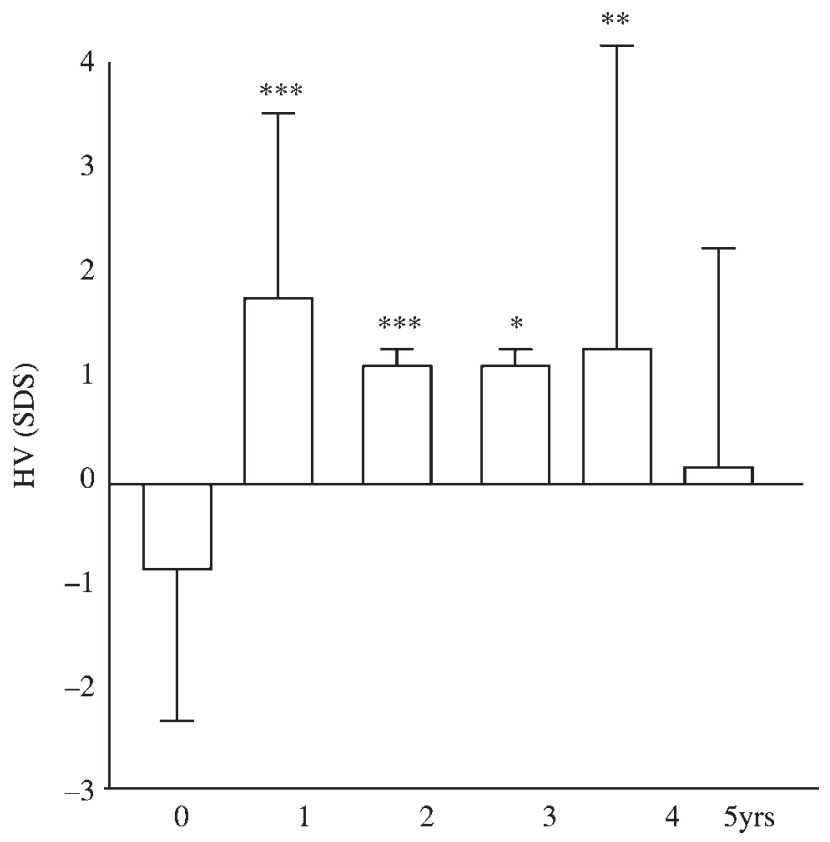

Figure 1 Mean ( \pm S.D.) HV before the start of treatment $(0)$ and during the 5 years of therapy. ${ }^{\star} P<0.01,{ }^{\star \star} P<0.005$, $\star \star \star P<0.0005$ compared with 0 .

years $(P<0.05)$, reaching its nadir during the 5 th year of therapy $(P<0.01)$. However, during the first 4 years of treatment the annual HV was always significantly higher than the baseline one (Fig. 1). Only during the 5th year was HV not significantly higher with respect to the pretreatment values (Fig. 1).

During the overall study period, bone maturation velocity did not significantly change, as demonstrated by the substantially stable $\mathrm{BA}: \mathrm{CA}$ ratio found 5 years after the onset of therapy in the entire series $(1.0 \pm 0.4$ vs $0.9 \pm 0.5)$.

\section{Height gain}

Thanks to the growth acceleration which followed the onset of GH therapy, a very important height gain was recorded throughout the 1st year of treatment. Afterwards the height gain progressively decreased during the subsequent years reaching its nadir during the 5th year (Fig. 2). During the entire treatment period the overall height gain was $1.46 \pm 0.88$ SDS.

To summarize, the average height deficiency under GH therapy significantly and progressively decreased from entry onwards, shifting from $-2.4 \pm 0.7$ to $-1.0 \pm 1.2$ SDS (Table 2). Therefore the prevalence of girls with pathological height deficiency (at least -2.0 SDS) progressively and significantly shifted from $75.9 \%$ at entry to $13.8 \%$ at the end of the treatment period (Table 2). All the four patients with persistent short stature had a X monosomy, but the prevalence of the 45,XO karyotype was not significantly different in these girls from those who achieved a normal 


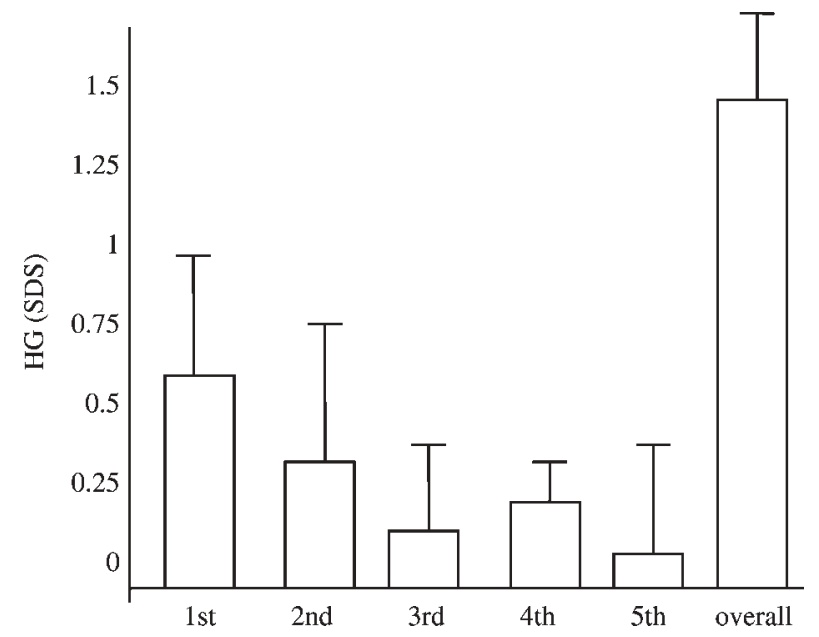

Figure 2 Mean ( \pm S.D.) height gain $(\mathrm{HG})$ during each year of therapy and the overall 5-year treatment period.

height after 5 years of treatment (4/4 vs 17/25; $\left.\chi^{2}=2.2, P>0.05\right)$. The less favorable height evolution of these four patients could not be predicted on the basis of either clinical (age at onset of therapy, coexistence of heart or kidney abnormalities) or auxological factors (birth weight, height at the onset of therapy, $\mathrm{TH})$.

Height at the final examination in the entire series was positively related to height SDS at the start of GH treatment $(r=0.7, P<0.001)$.

\section{PAH}

PAH progressively increased during the overall therapy period, shifting from $143.5 \pm 3.5 \mathrm{~cm}$ to $152.6 \pm 6.1 \mathrm{~cm}$ (Table 2). After 5 years of therapy, the average $\mathrm{PAH}$ was still significantly lower $(P<0.0025)$ with respect to the average $\mathrm{TH}(158.4 \pm 4.9 \mathrm{~cm})$. However, at the final evaluation, individual $\mathrm{PAH}$ values in the entire study cohort remained below the lowest limit of each patient's target range in only three patients (vs 20 at the onset of therapy; $\left.\chi^{2}=12.5, P<0.0005\right)$. Moreover, using the arbitrary height of $150 \mathrm{~cm}$ as

Table 2 Changes in height (references were healthy girls), prevalence of patients with subnormal height (at least $-2.0 \mathrm{SDS}$ ), $\mathrm{PAH}$ and $\mathrm{TH}$ minus $\mathrm{PAH}$ in the entire series during the 5-year treatment period.

\begin{tabular}{lcccc}
\hline & $\begin{array}{c}\text { Height } \\
(\text { SDS })\end{array}$ & Height $\leq-2$ SDS & $\begin{array}{c}\text { PAH } \\
(\%)\end{array}$ & $\begin{array}{c}\text { TH }- \text { PAH } \\
(\mathrm{cm})\end{array}$ \\
\hline Entry & $-2.4 \pm 0.7$ & 75.9 & $143.5 \pm 3.5$ & $14.7 \pm 6.0$ \\
1st year & $-1.8 \pm 0.8$ & 41.4 & $145.9 \pm 4.5$ & $12.5 \pm 4.7$ \\
2nd year & $-1.5 \pm 0.8$ & 20.7 & $148.4 \pm 4.9$ & $10.0 \pm 4.9$ \\
3rd year & $-1.4 \pm 0.9$ & 25.9 & $148.6 \pm 5.3$ & $9.8 \pm 5.5$ \\
4th year & $-1.1 \pm 1.0$ & 8.7 & $151.6 \pm 5.3$ & $6.8 \pm 6.1$ \\
5th year & $-1.0 \pm 1.2$ & 13.8 & $152.6 \pm 6.1$ & $5.8 \pm 6.9$ \\
$P$ & $<0.0001$ & $<0.0005$ & $<0.0005$ & $<0.0005$ \\
\hline
\end{tabular}

Significance levels are calculated between the 5 th year and baseline values. a threshold for 'normal stature', 22 of 29 girls $(75.8 \%)$ achieved a 'normal' PAH (vs two at entry; $\left.\chi^{2}=28.43, P<0.0005\right)$ at the final assessment.

Seven patients out of twenty-nine had no growth retardation (height above -2.0 SDS) at the onset of $\mathrm{GH}$ therapy. If compared with the 22 patients with pretreatment subnormal height these seven girls were taller both after the 1st year of therapy and at the end of study period and also their PAH was higher from the onset of therapy onwards (Table 3). Nevertheless, $\mathrm{TH}(\mathrm{PAH}$ at the conclusion of the study was not significantly different in these girls from the remaining ones (Table 3).

\section{Discussion}

Since the 1980s TS has been an accepted indication for GH treatment in many countries, although the effects of $\mathrm{GH}$ on adult height in these patients have been inconsistent $(3,10-13)$. There is no doubt that GH stimulates linear growth in girls with TS; nevertheless, reports describing relatively modest height gains have led some to question whether GH therapy will produce a meaningful increase in height in most patients with TS (14).

Furthermore, the best growth-promoting strategies in TS have not been clearly defined because of the different ages at which $\mathrm{GH}$ treatment has been started and the different $\mathrm{GH}$ doses used in the various studies (2, 15-18). Another misleading factor is the frequent associations of $\mathrm{GH}$ and oxandrolone or $\mathrm{GH}$ and estrogen adopted in many studies $(13,16,17)$.

In the present investigation, the prospective nature of our study design and the strict admission criteria have enabled us to ascertain the effects of early GH therapy alone on prepubertal linear growth. In fact, thanks to the early onset of treatment, the misleading influence of spontaneous pubertal development on growth rate was excluded in each case. Finally, the stable GH doses employed during the entire treatment period made it possible for us to evaluate whether and when a vanishing effect of the therapy could be expected $(5,15)$.

The first important finding of our study is represented by the prolonged height gain observed in infants and prepubertal children with TS under GH therapy alone. Thanks to this, at the end of the 5-year treatment period, the proportion of girls with persistently subnormal stature was very low. However, even in these few patients a further catch-up growth might occur before puberty, considering their low CA.

At the conclusion of our study period, $\mathrm{PAH}$ fell within the target range in almost all the patients. We cannot be sure that the final height of our patients will correspond with their PAH. However, Chernausek et al. (17) have found that the number of years on GH therapy prior to the introduction of estrogen was a strong predictor of the entire height gain (the equation was 
Table 3 Changes in height (references were healthy girls), $\mathrm{PAH}$ and $\mathrm{TH}-\mathrm{PAH}$ during the 5-year treatment period in the patients with pretreatment normal height (group A) and in those with pretreatment short stature (group B).

\begin{tabular}{|c|c|c|c|c|c|c|c|c|c|}
\hline & \multicolumn{3}{|c|}{ Height (SDS) } & \multicolumn{3}{|c|}{$\mathbf{P A H}(\mathrm{cm})$} & \multicolumn{3}{|c|}{ TH - PAH (cm) } \\
\hline & A & B & $P$ & $A$ & B & $P$ & $A$ & B & $P$ \\
\hline Entry & $-1.3 \pm 0.3$ & $-2.6 \pm 0.6$ & $<0.0025$ & $147.0 \pm 3.4$ & $142.4 \pm 2.7$ & $<0.0025$ & $11.6 \pm 4.2$ & $15.5 \pm 5.3$ & $<0.05$ \\
\hline 1st year & $-1.0 \pm 0.6$ & $-2.2 \pm 0.7$ & $<0.0025$ & $151.1 \pm 3.8$ & $144.2 \pm 3.2$ & $<0.0005$ & $8.9 \pm 5.7$ & $12.6 \pm 4.3$ & $<0.0025$ \\
\hline 5 th year & $0.1 \pm 1.8$ & $-1.2 \pm 1.1$ & $<0.05$ & $157.3 \pm 4.6$ & $151.6 \pm 6.1$ & $<0.05$ & $2.8 \pm 6.9$ & $6.9 \pm 5.1$ & n.s. \\
\hline
\end{tabular}

ns, not significant.

given simply: height gain in $\mathrm{cm}=2.1 \times$ years on $\mathrm{GH}$ before estrogen).

Early GH therapy not only allows a significant catchup growth in young girls with TS with short stature, but also prevents a precocious and severe height SDS loss $(18,19)$. This is another reason for starting treatment as early as possible, as is also the strong relationship between pretreatment and post-treatment statures found in the present TS series.

Little is known about the effects of GH in girls with TS whose height is still within the normal range for the general population (19). In the few girls of our cohort with normal pretreatment stature, catch-up growth under GH therapy was very similar to that recorded in those with subnormal height at entry.

Finally, our data support the concept that starting GH therapy at a younger age will permit the onset of estrogen therapy at an age of 11-12 years, in conformity with the patients' healthy peers, with psychological benefits and no risks of compromising adult stature (20). In our patients, in fact, $\mathrm{GH}$ treatment was initiated between 2 and 6 years of age, potentially allowing a 6 - to 10-year period of estrogen-free $\mathrm{GH}$ therapy before the limit of 11-12 years is attained.

To summarize, in the light of our findings we agree with Price \& Ranke (21) that it is justifiable to make efforts to diagnose girls with TS early, so that they can receive at least 4 years of estrogen-free $\mathrm{GH}$ treatment. Although our study population consisted of young girls only, a significant height deficiency (at least -2 SDS) was already detectable by the age 2 years and was present in a high proportion of the whole series. Moreover, the percentage of subjects with severe growth retardation (at least - 3 SDS) was not negligible. These findings altogether suggest that TS is a diagnosis to be suspected even in very young girls with growth failure, and that GH therapy may be started very early (18).

The choice of the most appropriate $\mathrm{GH}$ doses to be employed at the start of treatment and during the subsequent years is a greatly debated issue $(2,5,11,15)$. According to our results, an initial dose of $1.0 \mathrm{IU} / \mathrm{kg}$ per week seems to be sufficient to induce a striking acceleration of HV, at least in young girls and throughout the first year of treatment.

Escalating dosing regimens afterwards have been proposed in order to overcome the observed waning effect of $\mathrm{GH}$ treatment, resulting in a reduction of growth velocity after the first year of therapy (20). Such a suggestion seems to be partially supported by our patients' growth pattern during the overall treatment period. In the present study, in fact, the maintainance of a stable dose throughout the entire therapy period made it possible for us to document a progressive vanishing effect of $\mathrm{GH}$ treatment, particularly evident after the 4th year of therapy. Nevertheless, the TH$\mathrm{PAH}$ difference consistently diminished up to the end of the 5th year of therapy, which would suggest that the initial dose of $1.0 \mathrm{IU} / \mathrm{kg}$ per week was effective within the whole study period.

\section{Conclusions}

An effective growth-promoting strategy in TS should be based on early GH treatment, as is also suggested by our results. This strategy could result in a prepubertal normalization of height, thus allowing an appropriate time for the induction of puberty. An initial GH dose of $1.0 \mathrm{IU} / \mathrm{kg}$ per week may be suitable during the first years of therapy, as shown by our data documenting an important waning effect of $\mathrm{GH}$ therapy only after the 4th year of treatment. No acceleration of bone maturation was observed under this therapeutical regimen.

\section{References}

1 Hook EB \& Hamerton JL. The distribution of chromosomal genotypes associated with Turner's syndrome: livebirth prevalence rates and evidence for diminished fetal mortality and severity in genotypes associated with structural X abnormalities or mosaicism. Human Genetics $19836 \mathbf{6 4} 24-29$.

2 Van Teunenbrock A, de Muinck Keizer-Schrama SMPF, Stijnen T, Jansen M, Otten BJ, Delemarre-van de Waal HA, Vulsma T, Wit JM, Rouwe CW, Reeser HM, Gosen JJ, Rongen-Westerlaken C \& Drop SL. Yearly stepwise increments of the growth hormone dose results in a better growth response after four years in girls with Turner syndrome. Journal of Clinical Endocrinology and Metabolism $1996 \mathbf{8 1} 4013-4021$.

3 Rosenfeld RG, Attie KM, Frane J, Brasel JA, Burstein S, Cara JF, Chernausek S, Gotlin RW, Kuntze J, Lippe BM, Mahoney CP, Moore WV, Saenger P \& Johanson AJ. Growth hormone therapy of Turner's syndrome. Beneficial effect on adult height. Journal of Pediatrics $1998132319-324$.

4 Ross JL, McCauley E, Roeltgen D, Long L, Kushner H, Feuillan P \& Cutler GB Jr. Self-concept and behavior in adolescent girls with 
Turner syndrome: potential estrogen effects. Journal of Clinical Endocrinology and Metabolism 199681 926-931.

5 Saenger P. Growth-promoting strategies in Turner's syndrome. Journal of Clinical Endocrinology and Metabolism $1999 \mathbf{8 4}$ 4345-4348.

6 Sempè M, Pedron G \& Roy-Pernot MP. In Auxologie, Methode et Sèquences. Paris: Theraplix, 1997.

7 Tanner JM, Goldstein H \& Whitehouse RH. Standards for children's heights at age 2-9 years allowing for height of parents. Archives of Disease of Childhood 197045 755-762.

8 Lyon AJ, Preece MA \& Grant DB. Growth curve for girls with Turner syndrome. Archives of Disease of Childhood $1985 \mathbf{6 0}$ 932-935.

9 Greulich WW \& Pyle SI. Radiographic Atlas of Sceletal Development of the Hand and Wrist, edn 2. Stanford, CA: Stanford University Press, 1995.

10 Van den Broeck J, Massa GG, Attanasio A, Matranga A, Chaussain JL, Price DA, Aarskog D \& Wit JM. Final height after long-term growth hormone treatment in Turner syndrome. Journal of Pediatrics $1995 \mathbf{1 2 7} 729-735$.

11 Massa G, Otten BJ, de Muinck Keizer-Schrama SMPF, Delemare van de Waal HA, Jansen M, Vulsma T, Oostdijk W, Waelkens JJ \& Wit JM. Treatment with two growth hormone regimes in girls with Turner syndrome: final height results. Hormone Research $199543144-146$.

12 Haeusler G, Schmitt K, Blumel P, Plochl E, Waldhor T \& Frisch H. Growth hormone in combination with anabolic steroids in patients with Turner syndrome: effect on bone maturation and final height. Acta Paediatrica 199685 1408-1414.

13 Nilsson KO, Albertsson-Wikland K, Alm J, Aronson S, Gustafsson J, Hagenas L, Hager A, Ivarsson SA, Karlberg J, Kristrom B, Marcus C, Moell C, Ritzen M, Tuvemo T, Wattsgard C, Westphal $\mathrm{O} \&$ Aman J. Improved final height in girls with Turner's syndrome treated with growth hormone and oxandrolone. Journal of Clinical Endocrinology and Metabolism 199681 635-640.
14 Donaldson MDC. Jury still out on growth hormone for normal short stature and Turner's syndrome. Lancet $1985 \mathbf{3 7 8} 3-4$.

15 Sas TC, De Muinck Keizer-Schrama SMPF, Stijnen T, Jansen M, Otten BJ, Gear Hoorweg-Nijman JJ, Vulsma T, Massa GG, Rouwe CW, Reeser HM, Gerver WJ, Gosen JJ, Rongen-Westerlaken C \& Drop SL. Normalization of height in girls with Turner syndrome after long-term growth hormone treatment: results of a randomized dose-response trial. Journal of Clinical Endocrinology and Metabolism 199984 4607-4612.

16 Naeraa RW, Kastrup KW \& Nielsen J. Treatment in Turner syndrome with a low dose peroral $17 \beta$-estradiol alone, or in combination with growth hormone. In Basic and Clinical Approach to Turner Syndrome, pp 209-214. Eds I Hibi \& K Takano. Amsterdam: Elsevier Science Publishers BV.

17 Chernausek SD, Attie KM, Cara JF, Rosenfeld RG \& Frane J. Growth hormone therapy of Turner syndrome: the impact of age of estrogen replacement on final height. Journal of Clinical Endocrinology and Metabolism 200085 2439-2445.

18 Reiter EO, Blethen SL, Baptista J \& Price L. Early initiation of growth hormone treatment allows age-appropriate estrogen use in Turner's syndrome. Journal of Clinical Endocrinology and Metabolism 200186 1936-1941.

19 Linglart A, Carel J, Cabrol S, Berlier P, Stuckens C, Wagner K, de Keranet M, Limoni C \& Chaussain J. Early growth hormone treatment $(\mathrm{GH})$ in girls with Turners' syndrome: towards prevention of short stature. Hormone Research 200258 (Suppl 2) 159.

20 Gravholt CH. Aspects of the treatment of Turner syndrome. Expert Opinion on Pharmacotherapy 20012 1633-1647.

21 Price DA \& Ranke MB. Growth hormone in Turner syndrome. Archives of Disease in Childhood $200184525-526$.

Received 25 March 2004

Accepted 21 July 2004 